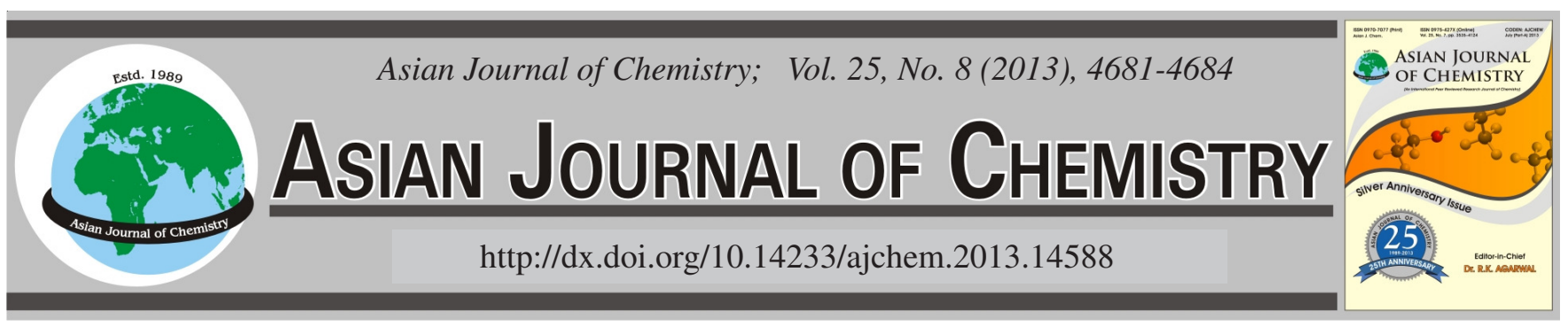

\title{
Thermal Uniformity Analysis of Polar and Non-polar Solvents During Heating Based on Numerical Calculation
}

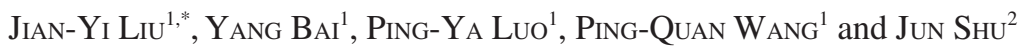

\begin{abstract}
${ }^{1}$ State Key Laboratory of Oil and Gas Reservoir Geology and Exploitation, Southwest Petroleum University, Chengdu 610500, P.R. China
\end{abstract} ${ }^{2}$ College of Electronics and Information Engineering, Sichuan University, Chengdu 610065, P.R. China

*Corresponding author: E-mail: baiyanghyq@foxmail.com

(Received: 17 September 2012;

Accepted: 20 February 2013)

AJC-13043

\begin{abstract}
It is a key issue to obtain uniform heating in certain regions of an applicator. In this paper, the non-polar $\left(\mathrm{CCl}_{4}\right)$ and polar (water) solvents are heated together in same container. The silicon-carbide is chose to be a vessel. The uniformities of temperature were analyzed using finite-element method under different configurations during heating. The results show that the temperature uniformity is influenced by solvent volume size and volume ratio and the thermal energy transfers from the non-polar to polar solvent for temperature difference. When the improvement in temperature uniformity is not obvious, it can improve significantly the uniformity of temperature by changing the volume or volume ratio.
\end{abstract}

Key Words: Thermal uniformity, Polar and Non-polar Solvents, Numerical calculation, Silicon carbide.

\section{INTRODUCTION}

It is known that solvents are classified on the basis of their polarity. Molecules with large dipole moments and high dielectric constants are considered polar and those with low dipole moments and low dielectric constants are considered non-polar.

(1) Highly polar molecules have a network of hydrogen bonding between their molecule e.g. water; (2) Polar solvents have a replaceable hydrogen atom and an element like nitrogen or oxygen, e.g. methanol; (3) Intermediately polar solvents have an element like nitrogen or oxygen, but no replaceable hydrogen atom, e.g. acetonitrile; (4) Non-polar compounds neither have replaceable hydrogen nor electronegative element in their molecule $e . g$. benzene or other hydrocarbons.

Interestingly carbon tetra chloride, despite of having chlorine in it is a non-polar compound, since the structure of the compound is such that the there is nullification of dipole moments due to identical and opposite bonds between carbon and chlorine.

Most chemical reactions are sensitive to temperature, therefore using microwaves to heat reactants presents an impressive application prospect ${ }^{1,2}$. At present, in the reactions assisted and catalyzed, the majority of reaction solvents are polar in order that they are heated preferably. However, the non-polar solvents are also commonly used in a number of chemical reactions.
In this paper, the method of heating is not traditional heating, but microwave heating. Compared with traditional heating, microwave energy is delivered directly to materials through molecular interactions with the electromagnetic field ${ }^{3}$. Thus microwave heating has the advantages such as lesser time and energy savings, easy to control as well as clean heating etc., which present an impressive application prospects ${ }^{4}$.

In this paper, a numerical model is presented to study the temperature distribution of heterogeneous mixture reaction solution under microwave radiation. The uniformity is well analyzed when the solvent of polar and non-polar is mixed.

\section{EXPERIMENTAL}

In the simulation of microwave heating on chemical reactions, we have to know the function of the effective permittivity with respect to temperature. Generally, the effective permittivity of reactants changes with temperature. The coupled Maxwell's equations, fluid field equations and heat transport equations were solved by using finite-element method. The flow chart of the numerical calculation of multiphysics is shown in Fig. 1 and the calculation model is shown in Fig 2.

In this paper, $\mathrm{CCl}_{4}$ is a typical non-polar solvent widely used in synthetic chemistry research. The permittivity of water was taken from reference ${ }^{5}$, which is $\varepsilon_{\mathrm{r}}=2.24-\mathrm{j}^{*} 0.002$. The silicon-carbide $(\mathrm{SiC})$ is chose to be a vessel. With regard to $\mathrm{SiC}$, materials (i.e. a solvent or a reaction mixture) contained inside the container will be effectively shielded from the 
electromagnetic field ${ }^{6}$. The permittivity of $\mathrm{SiC}$ changes with temperatures, so it is necessary to establish a function between the permittivity and temperature. From the work of Damm and Kappe ${ }^{7,8}$, the relation between $\varepsilon_{\mathrm{r}}$ and temperature is gained as formula (1) by the method of curve-fitting.

$$
\varepsilon_{\mathrm{r}}=6.52-\mathrm{j} *(-6.40786+0.02347 * \mathrm{~T})
$$

where $\mathrm{T}$ is the temperature.

Water is a typical polar solvent widely used in synthetic chemistry research. This paper therefore focused on the heating of water and $\mathrm{CCl}_{4}$ in $\mathrm{SiC}$ container with different configurations and size.

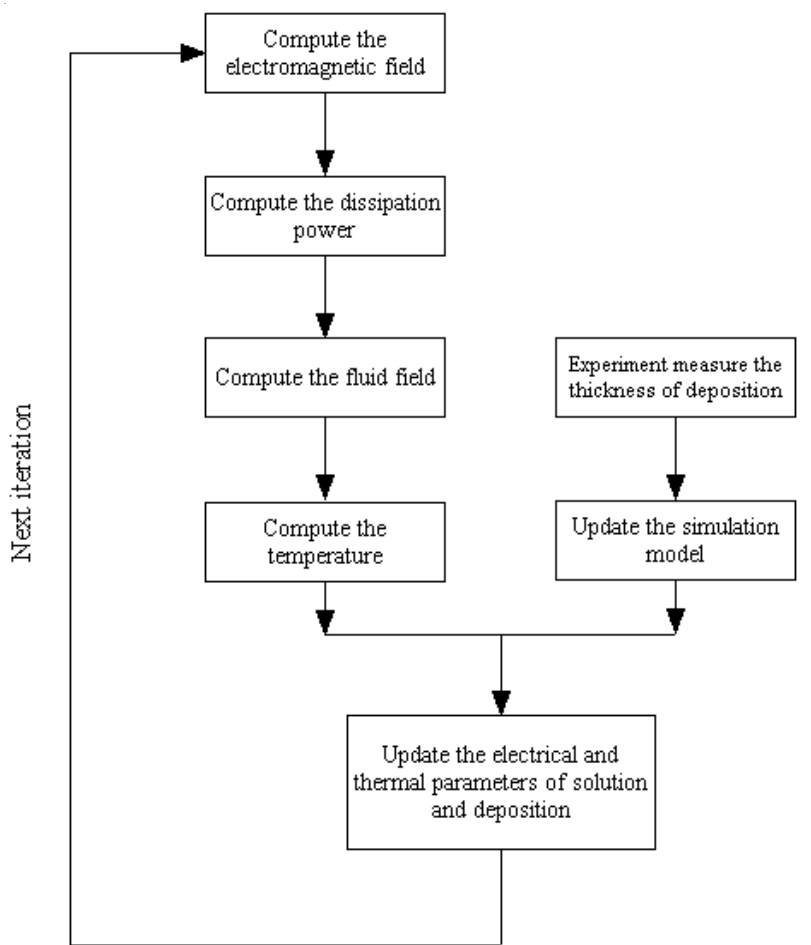

Fig. 1. Flow chart of the numerical calculation of multiphysics

During all the computational process, the input power at the waveguide feeding has been set to $\mathrm{P}=700 \mathrm{~W}$. The microwave heating time is $t=5 \mathrm{~s}$. Relative parameters which are used to solve the case are listed in Table-1.

\begin{tabular}{lccc}
\multicolumn{4}{c}{ TABLE-1 } \\
RELATIVE PARAMETERS \\
Parameter & $\mathrm{SiC}$ & $\mathrm{CCl}_{4}$ & Water \\
\hline Heat conduction: $\mathrm{k}\left(\mathrm{w} / \mathrm{m}^{*} \mathrm{~K}\right)$ & 20 & 0.106 & 0.6096 \\
Density: $\rho\left(\mathrm{kg} / \mathrm{m}^{3}\right)$ & 3200 & 1595 & 997 \\
Atmospheric heat capacity: $\mathrm{C}_{\mathrm{p}}(\mathrm{J} /(\mathrm{kg} * \mathrm{~K}))$ & 170 & 854 & 4181 \\
\hline
\end{tabular}

By calculation, the results such as maximum and minimum value of temperature were recorded during heating. Then the uniformities of electric field and temperature were obtained respectively by formula (2). The average temperature was achieved by formula (3).

$$
\text { Temperature uniformity }=\sqrt{\frac{T_{\text {max }}^{2}-T_{\text {min }}^{2}}{T_{\text {max }}^{2}}}
$$

$\mathrm{T}_{\max }$ is the maximum temperature and $\mathrm{T}_{\min }$ is minimum temperature.

$$
\text { Average temperature }=\frac{\sum_{i=1}^{\infty} \mathrm{T}_{i}}{\mathrm{~V}}
$$

$\mathrm{T}_{\mathrm{i}}$ is the temperature for every grid of heated solvent and $\mathrm{V}$ is the total volume.

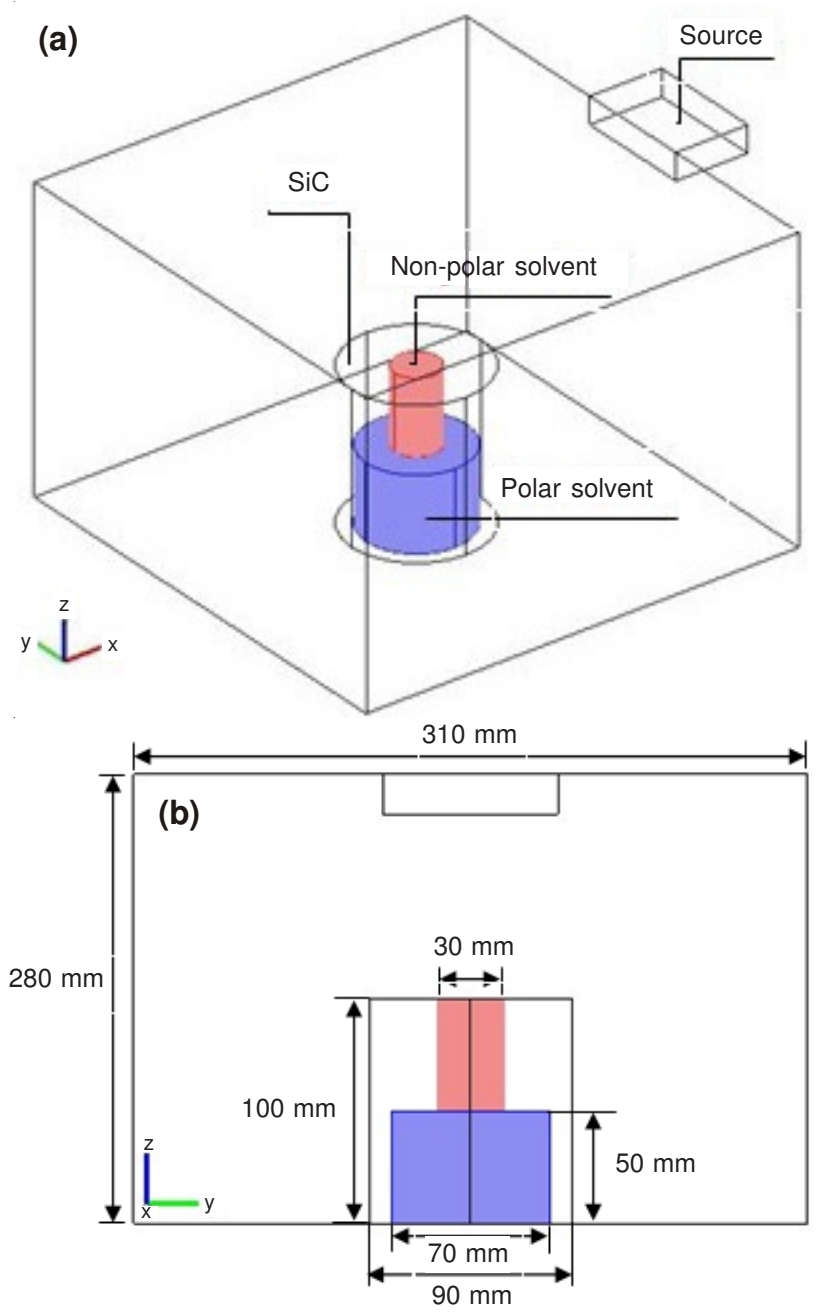

Fig. 2. Physical model of experiment system: (a) 3D model; (b) 2D model

\section{RESULTS AND DISCUSSION}

By calculation, the resulted temperature distributions under the different proportion with non-polar and polar solvent were shown in Fig. 3.

It is observed that the heated effect of $\mathrm{CCl}_{4}$ is more obvious than water and the temperature is high relatively. As we can see, the energy is flowing from $\mathrm{CCl}_{4}$ to water. It is proved that the thermal energy transfers from non-polar solvent to polar solvent.

According to calculation results, the maximum and minimum values of the temperature were recorded during the heating process. Finally, the uniformity of the temperature was calculated by the formula (2). The results from different radius and volume ratio for the $\mathrm{CCl}_{4}$ and water are listed in Tables 2 and 3 .

From Fig. 3 and Table-2, one can observe that the uniformity radius $40 \mathrm{~mm}$ is superior to others when the volume ratio of $\mathrm{CCl}_{4}$ and water is $1: 1$. The effect of heating solvent is desired 

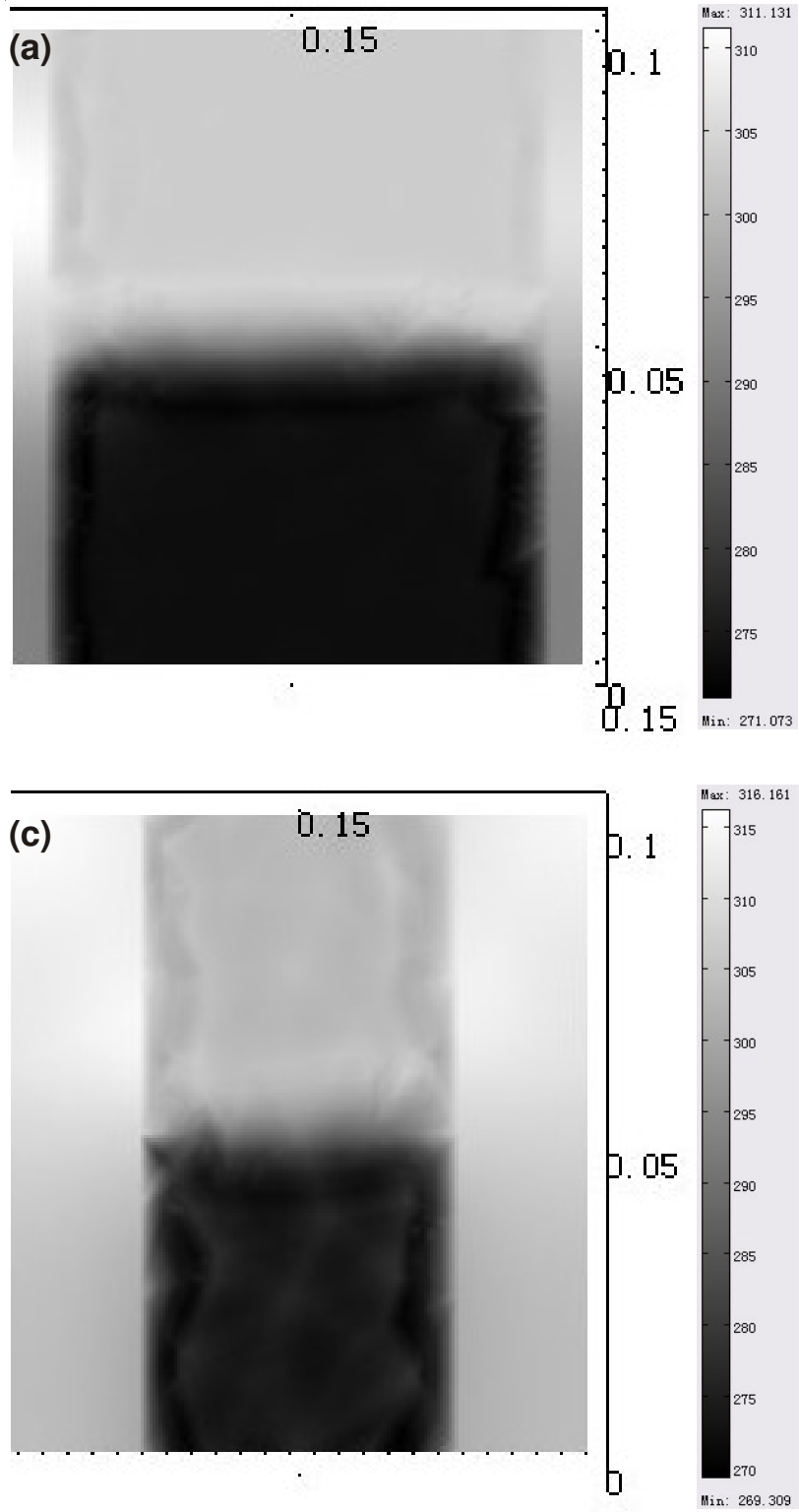
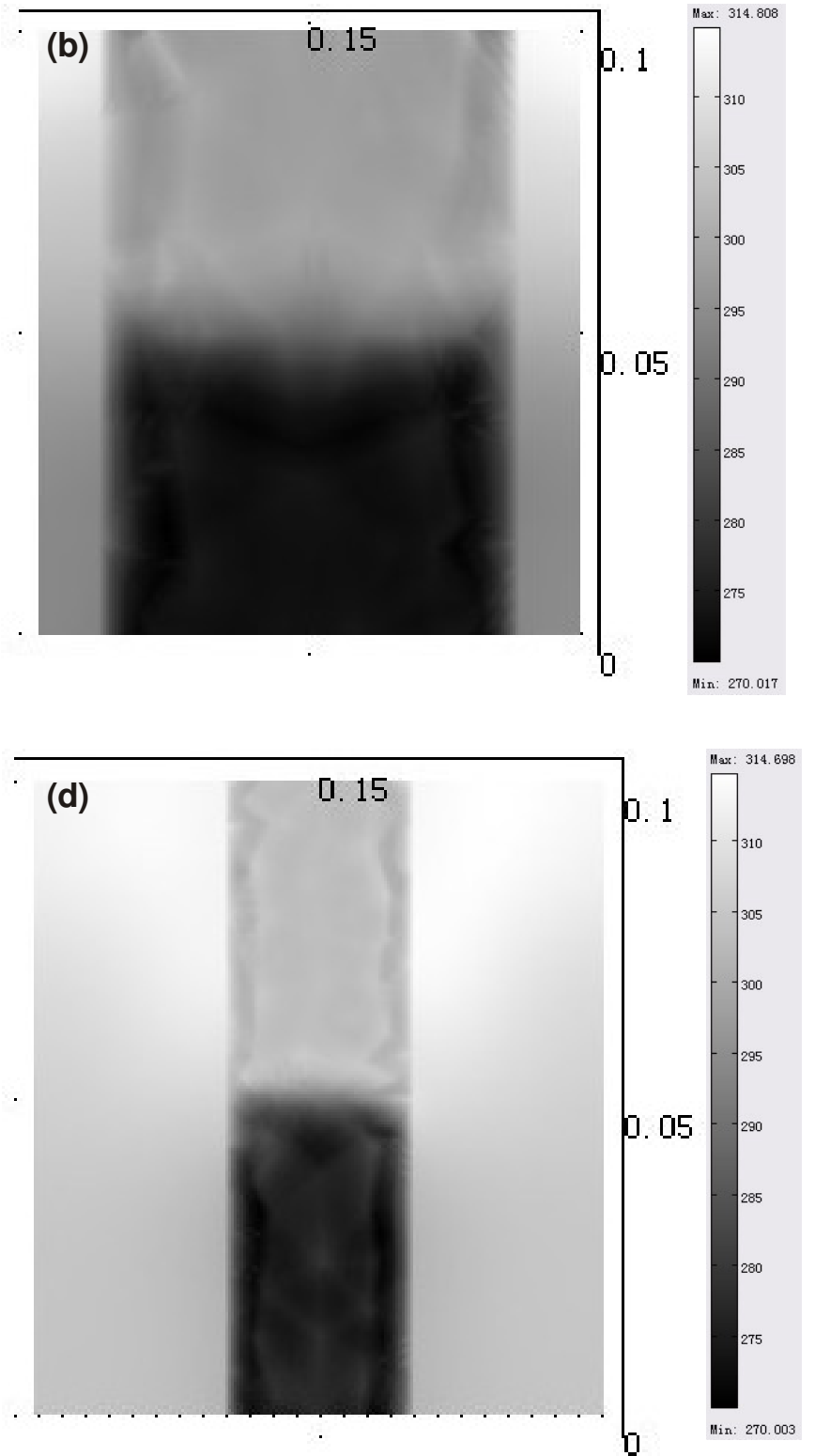

Fig. 3. Temperature distribution with different radius when the volume ratio is $1: 1$ (unit: $\mathrm{K}$ ); (a) The radius of $\mathrm{CCl}_{4}$ and water is 40 mm; (b) The radius of $\mathrm{CCl}_{4}$ and water is $35 \mathrm{~mm}$; (c) The radius of $\mathrm{CCl}_{4}$ and water is $25 \mathrm{~mm}$ (d) The radius of $\mathrm{CCl}_{4}$ and water is $15 \mathrm{~mm}$

using $\mathrm{SiC}$ as the vessel material. It is proved that the container will be effectively shielded from the electromagnetic field. The thermal energy in $\mathrm{SiC}$ container is found to transfer from $\mathrm{CCl}_{4}$ to water. Besides, by comparing with different volume ratio of $\mathrm{CCl}_{4}$ and water from Fig. 4 and Table-3, the uniformity is best when the volume ratio of $\mathrm{CCl}_{4}$ and water is 49: 9 . So it is obvious that the temperature uniformities were influenced by different solvent volumes, the uniformity of temperature can be highly improved by changing the volume.

\begin{tabular}{ccccc}
\multicolumn{5}{c}{ TABLE-2 } \\
\multicolumn{5}{c}{ RESULTS WITH DIFFERENT RADIUS OF CCl ${ }_{4}$} \\
\hline $\begin{array}{c}\text { Radius } \\
(\mathrm{mm})\end{array}$ & $\mathrm{T}_{\max }(\mathrm{K})$ & $\mathrm{T}_{\min }(\mathrm{K})$ & $\begin{array}{c}\text { Average temperature: } \\
\mathrm{T}_{\text {avg }}\left(\mathrm{K}^{3} \mathrm{~m}^{3}\right)\end{array}$ & $\begin{array}{c}\text { Temperature } \\
\text { uniformity }\end{array}$ \\
\hline 40 & 311.131 & 271.073 & 291.142 & 0.491 \\
35 & 314.808 & 270.017 & 292.431 & 0.858 \\
25 & 316.161 & 269.309 & 292.752 & 0.852 \\
15 & 314.698 & 270.003 & 292.324 & 0.856 \\
\hline
\end{tabular}

\begin{tabular}{ccccc}
\multicolumn{5}{c}{ TABLE-3 } \\
$\begin{array}{ccccc}\text { RESULTS WITH DIFFERENT VOLUME } \\
\text { RATIO OF CCl }{ }_{4} \text { AND WATER }\end{array}$ \\
\hline $\begin{array}{c}\text { The volume } \\
\text { ratio of } \mathrm{CCl}_{4} \\
\text { and water }\end{array}$ & $\mathrm{T}_{\max }(\mathrm{K})$ & $\mathrm{T}_{\min }(\mathrm{K})$ & $\begin{array}{c}\text { Average } \\
\text { temperature: } \\
\mathrm{T}_{\text {avg }}\left(\mathrm{K} / \mathrm{m}^{3}\right)\end{array}$ & $\begin{array}{c}\text { Temperature } \\
\text { uniformity }\end{array}$ \\
\hline $9: 49$ & 320.477 & 270.148 & 295.375 & 0.538 \\
$49: 9$ & 307.396 & 269.871 & 288.656 & 0.479 \\
$25: 64$ & 324.132 & 270.773 & 297.485 & 0.550 \\
$64: 25$ & 311.251 & 269.098 & 290.192 & 0.503 \\
\hline
\end{tabular}

\section{Conclusion}

In this paper, due to microwave absorption of the nonpolar and polar solvent is different, silicon carbide with the high microwave absorption properties is used to be the heated vessel and $\mathrm{CCl}_{4}$ as the non-polar solvent and water as polar solvent. By calculation, it is proved that the temperature uniformity is influenced by solvent volume size and volume ratio when the non-polar and polar solvents are heated together 

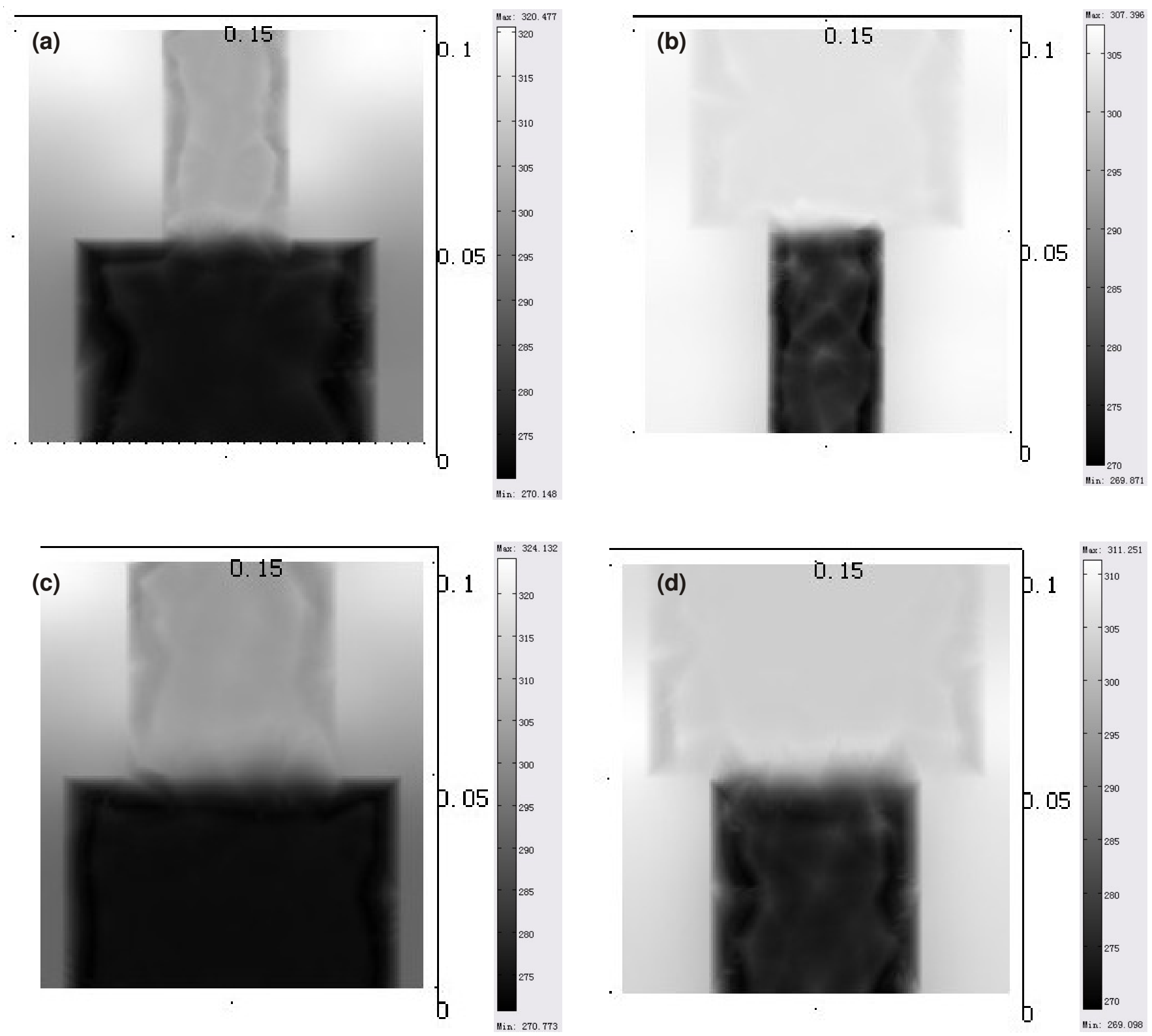

Fig. 4. Temperature distribution with different volume ratio (unit: $\mathrm{K}$ ); (a) The volume ratio of $\mathrm{CCl}_{4}$ and water is 9:49. (b) The volume ratio of $\mathrm{CCl}_{4}$ and water is 49:9. (c) The volume ratio of $\mathrm{CCl}_{4}$ and water is 25:64. (d) The volume ratio of $\mathrm{CCl}_{4}$ and water is 64:25

in same container. Besides, it is occurred that the thermal energy transfers from the non-polar to polar solvent for temperature difference. When the improvement in temperature uniformity is not obvious, it can improve significantly the uniformity of temperature by changing the volume or volume ratio.

\section{ACKNOWLEDGEMENTS}

This work was supported by the Seventh Installment of Graduate Innovation Fund of Southwest Petroleum University, Grant No: GIFSB0704.

\section{REFERENCES}

1. A.C. Metaxas, Foundations of Electroheat, John Wiley \& Sons, Chichester, UK (1996).

2. Dielectric Heating for Industrial Processes, U.I.E. Dielectric Heating Working Group, Paris (1992).

3. R. Meredith, Engineers Handbook of Industrial Microwave Heating, London: Institute of Electrical Engineers (1998).

4. C.O. Kappe, Chem. Soc. Rev., 37, 1127 (2008).

5. Higher Education Press: Physical and Chemical Experiment (ver. 2nd), China, 264 (1989).

6. D. Obermayer, B. Gutmann and C.O. Kappe, Angew. Chem., Int. Ed., 48, 8321 (2009).

7. M. Damm and C.O. Kappe, J. Comb. Chem., 11, 460 (2009)

8. M. Damm and C.O. Kappe, Mol. Diversity, 13, 529 (2009). 